Hispania Sacra, LX

121, enero-junio 2008, 267-295, ISSN: 0018-215-X

\title{
PLAN DE REFORMA DE LA IGLESIA ESPAÑOLA IMPULSADO POR NAPOLEÓN BONAPARTE
}

\author{
POR \\ LUIS BARBASTRO GIL \\ Licenciado en Teología y Doctor en Historia
}

\begin{abstract}
RESUMEN
El artículo aborda el plan de reforma de la Iglesia española, desconocido hasta hoy, impulsado por Napoleón Bonaparte en 1808 y elaborado por un equipo dirigido por monseñor de Pradt, base de la política religiosa del gobierno josefino. Al análisis global del clero español le sigue la exposición de las distintas medidas de reforma planteadas en dicho informe, así como una valoración crítica de esta reforma por parte del autor.
\end{abstract}

PALABRAS ClAVE: Napoleón, Abate Pradt, Reforma del clero, Clero español.

\begin{abstract}
This article deals with a subject unknown up to the present, the plan of reformation carried out by the Spanish Catholic Church. This plan was promoted by Napoleon Buonaparte in 1808 and put into practice by a team led by Monsignor de Pradt, who was at the basis of the religious policy followed by Buonaparte's gouvernement. The article analyses the Spanish clergy, and presents the reformation measures that were undertaken, together with a critical assessment of the said reformation.
\end{abstract}

KEY WORDS: Napoleon Buonaparte, Monsignor de Pradt, the Reformation measures, of Spanish clergy.

Recibido/Received 15-10-2007

Aceptado/Accepted 15-12-2007

El año 1808 significa, como se ha dicho reiteradamente, una fecha crucial para la historia contemporánea de España, al haberse registrado a lo largo de él acontecimientos de una singular trascendencia: caída de la monarquía de Car- 
los IV; acceso efímero de Fernando VII al trono; inicio del reinado josefino tras las abdicaciones de Bayona; conflicto bélico con los franceses que duraría hasta 1814; afloración de ideales reformistas y revolucionarios promovidos por los pensadores que algunos han denominado la generación de 1808. Pero, ante todo, como escribiera con acierto Julián Marías, 1808 fue el año que precipitó tras la invasión francesa la discordia latente entre los españoles y provocó el drama de las «dos Españas», que de forma manifiesta o larvada perduraría a lo largo del siglo XIX.

La Iglesia española no sólo no fue ajena a todos estos acontecimientos, sino que se vio intensamente afectada por ellos. Desde 1808 hasta 1814 el catolicismo español y, en particular, el clero atravesaron uno de los periodos más convulsos de su historia. La religión se vio asediada por influencias ambientales e ideológicas que nunca se habían manifestado antes con tanta virulencia. Fue en estas circunstancias tan adversas en las que se ideó el plan de reforma eclesiástica impulsado por Napoleón Bonaparte y que tratamos de exponer en las páginas siguientes. Un plan de reforma hasta ahora desconocido, que sale a la luz cuando conmemoramos precisamente el bicentenario de la Guerra de la Independencia o Guerra contra Napoleón, impregnada de un claro sentido «religioso», y cuyas consecuencias no han sido valoradas todavía de manera suficiente. Con este trabajo pretendemos modestamente contribuir al conocimiento de lo que se ha dado en llamar la crisis del antiguo régimen en España, a la vez que intentamos poner de manifiesto el papel relevante de la Iglesia católica española en los inicios del siglo XIX.

\section{FUNDAMENTOS IDEOLÓGICOS Y LÍNEAS MAESTRAS DEL PLAN DE REFORMA}

Uno de los retos más importantes en los albores del siglo XIX español era, sin duda, la reforma de la Iglesia, al haberse convertido por su estructura administrativa y económica en un Estado dentro del Estado ${ }^{1}$. En esta dirección se habían orientado ya las tímidas medidas impulsadas por los ministros regalistas de Carlos III y, en el reinado de Carlos IV, por algunos ministros como Urqui-

\footnotetext{
${ }^{1}$ En relación a la Iglesia española y en especial al clero durante el primer tercio del siglo XIX remitimos a las siguientes obras: M. ARTOLA, Los orígenes de la España contemporánea, Madrid, 1975, I, pp. 38-52; M. Revuelta, Política religiosa de los liberales en el siglo XIX. Trienio constitucional, Madrid, 1973, pp. 22-52; W. J. Callahan, Iglesia, poder y sociedad en España, 1750-1874, Madrid, 1989, pp. 77-110. Para un conocimiento específico del clero a nivel regional, resultan útiles las siguientes investigaciones: G. Feliu, La clerecía catalana durant el trienni liberal, Barcelona, 1972; L. Higueruela, La diócesis de Toledo durante la Guerra de la Independencia española, Toledo, 1981; L. BARBASTRO, El clero valenciano en el Trienio liberal, Alicante, 1985. Un estudio documentado del clero español en la época moderna (siglos XV al XVIII) es el que nos ofrece M. BARRIO en su obra El clero en la España moderna (en prensa).
}

Hispania Sacra, LX

121, enero-junio 2008, 267-295, ISSN: 0018-215-X 
$\mathrm{jo}^{2}$, apoyados por un grupo de eclesiásticos y seglares partidarios de la reforma, a quienes sus detractores calificaron de «jansenistas» ${ }^{3}$.

Hasta ahora algunos estudiosos del primer liberalismo español habían puesto de relieve la influencia que el sínodo de Pistoia e incluso la Constitución Civil del Clero habían tenido en los proyectos de reforma eclesiástica de las Cortes de Cádiz ${ }^{4}$, y sobre todo en el Trienio. Un periodo este último en el que se aprobaron diferentes decretos (medio diezmo, supresión y reforma de regulares, desamortización parcial, supresión de beneficios eclesiásticos, etc.) y se presentaron a las Cortes dos planes generales de reforma eclesiástica. El segundo de ellos fue expuesto a las segundas Cortes en 1823, y su dictamen estaba inspirado en las doctrinas radicales del otrora josefino y reformista moderado, Juan Antonio Llorente 5 .

Dichos historiadores consideraban con algún fundamento que había sido en Cádiz donde se inició el áspero camino de la reforma eclesiástica recorrido exclusivamente por el liberalismo español. Sin embargo, el documento que presentamos demuestra que fue durante el gobierno de José I cuando se establecieron por primera vez las bases de una reforma estructural de la Iglesia española, más revolucionaria que la aprobada por los diputados de Cádiz, y semejante en no pocos aspectos a la reforma del Trienio, de la que fue su verdadero precedente.

El plan de reforma impulsado por Napoleón Bonaparte comenzó a elaborarse a partir de diciembre de 1808, coincidiendo con la presencia de aquél en España, que supuso la ocupación nuevamente de Madrid por las tropas francesas. Fue precisamente en Chamartín, lugar cercano a la capital, donde el Emperador firmó el día 4 de ese mes los famosos ocho decretos por los que se asestaba un duro golpe a la nobleza, a las instituciones y a la Iglesia española.

2 R. Herr, España y la revolución del siglo XVIII, Madrid, 1971, pp. 352-358; J. L. VILLANUEVA, Vida literaria, I. Edición, introducción y notas de Germán Ramírez Aledón, Alicante, 1996, pp. 151157; Emilio LA PARRA LóPEZ, «Iglesia y grupos políticos en el reinado de Carlos IV», Hispania Nova, (2002) 4-7.

3 J. Marichal, El secreto de España, Madrid, 1995, pp. 18-28; Luis BARBASTRo GIL, «El «catolicismo liberal» de Villanueva, Bernabeu y Cortés. Una contribución decisiva al primer liberalismo (1808-1823)», Spagna contemporánea, 26 (2004) 1-3.

${ }^{4}$ E. LA PARra, El primer liberalismo y la Iglesia. Las Cortes de Cádiz, Alicante, 1985, p. 24.

5 Sobre la influencia de Juan Antonio Llorente en ese segundo plan, puede verse el esclarecedor artículo de M. Revuelta GonZÁLEZ, «Los planes de reforma eclesiástica durante el Trienio Constitucional», Miscelánea Comillas, 30 (1972), 92-123; 329-348. Las polémicas intervenciones de los eclesiásticos valencianos en las Cortes del Trienio, en particular del alicantino Antonio Bernabeu, han sido analizadas en el libro de L. BARBASTRo, Revolución liberal y reacción (1808-1833). Protagonismo ideológico del clero en la sociedad valenciana, Alicante, 1987, pp. 164 ss. En cuanto a la frustración de una reforma eclesiástica estructural en el primer liberalismo español, véase M. TERUEL, Obispos liberales, Lleida, 1996, pp. 245-262. 
En lo que atañe a esta última, se suprimió la Inquisición -uno de los baluartes del ultramontanismo- y se redujo el número de conventos, con el pretexto de que eran excesivos y resultaban perjudiciales para el progreso de la nación ${ }^{6}$. Una argumentación esgrimida también, como veremos, por los autores del plan de reforma, orientado esencialmente a someter al clero al poder del Estado, utilizando sus recursos para reorganizar la economía y aliviar el déficit público. En este sentido, baste recordar que la Deuda nacional se elevaba en julio de 1808 a 6.441,2 millones de reales, y devengaba un crédito de 195,9 millones al año ${ }^{7}$.

La redacción de ese importante plan de reforma corrió a cargo de un grupo dirigido por el abate de Pradt, capellán mayor de Napoleón y arzobispo de Malinas8; éste se desplazó a España por expreso deseo del Emperador, a quien acompañó en su viaje ${ }^{9}$, recibiendo de él algunas confidencias, a las que aludiría años más tarde en sus Mémoires historiques. Dicho documento fue enviado por Pradt a José I en marzo de 1809 a través del conde Roederer, senador y principal interlocutor de los dos hermanos desde París ${ }^{10}$.

Creemos que los colaboradores de Pradt contaron desde el primer momento con algunos informes provenientes del ministerio de Negocios Eclesiásticos dirigido por Azanza, de la Secretaría de Estado en manos de Urquijo, y de la de Hacienda, presidida por Cabarrús, según se desprende de los datos que sirvieron de base. Todos ellos, de conocidas aficiones reformistas y regalistas, habían manifestado de un modo u otro antes de 1808 la necesidad urgente de una reforma de la Iglesia española.

6 M. Revuelta, «La Iglesia española ante la crisis del Antiguo Régimen (1808-1833)», en R. García Villoslada, Historia de la Iglesia en España, Madrid, 1979, tomo V, pp. 16-17.

7 Archives Nationales. París (en adelante AN), 381 Archive Privée Joseph Bonaparte (en adelante AP), leg. 14.

${ }^{8}$ El abate de Pradt (1759-1837) había sido diputado ultrarrealista en los Estados Generales, siendo desterrado por su oposición a las medidas radicales de los revolucionarios; regresó a Francia en 1801 tras firmarse el Concordato, y fue nombrado Capellán Mayor de Napoleón y, más tarde, obispo de Poitiers (1804) y arzobispo de Malinas (1808). Eclesiástico inteligente pero acomodaticio, acompañó a Napoleón a Bayona y en su posterior expedición militar a la Península. Su abundante literatura histórica acerca de España ha sido analizada minuciosamente por Jean-René AYMES en «El abate de Pradt y España» (1 $1^{\mathrm{a}}$ y $2^{\mathrm{a}}$ parte), Trienio. Ilustración y liberalismo, 5 (1985) 3-35, y 7 (1986) 3-41. Por su parte, el jesuita M. Aguirre estudió a su vez el influjo de Pradt en los independentistas americanos, en su obra El abate de Pradt en la emancipación hispanoamericana (1800-1833), reeditada por el Instituto de Investigaciones Históricas, Santiago de Chile, 1983.

${ }^{9}$ AN. 381 AP, pièce 17, dossier 2, cahier 1. Carta del conde Roederer a José I, París, 20 de marzo de 1809. A esta carta acompaña un legajo con el título Table de matières (s.d.) y (s.n.), relativo al plan de reforma eclesiástica española.

${ }^{10}$ Idem. El conde Pierre Louis de Roederer (1754-1835) fue diputado en la Asamblea Constituyente, pasando a la clandestinidad al comienzo de la Convención Montaña; volvió a Francia tras el golpe del 18 Brumario, formando parte del Senado junto a Sieyès, Destutt de Tracy y Grègoire. Hábil diplomático y experto en finanzas, había sido ministro de José I en Nápoles (1806), y era la persona que éste quería como embajador en Madrid, en lugar del conde La Forest, sin conseguirlo.

Hispania Sacra, LX

121, enero-junio 2008, 267-295, ISSN: 0018-215-X 
No sabemos si entre esos colaboradores estaba Juan Antonio Llorente, canónigo y Maestrescuela de la catedral de Toledo, recién nombrado consejero de Estado. El fue quien aupado al poder por su gran amigo el coronel Francisco Amorós ${ }^{11}$, envió a Napoleón su famoso «Reglamento para la Iglesia española»; un documento que comprendía un amplio estudio acerca de la organización eclesiástica, y que había terminado de escribir pocos días antes de acudir a la Asamblea de Bayona ${ }^{12}$. Pese a todo ello no parece que la colaboración de Llorente, si es que se produjo, fuera relevante.

Así al menos se deduce de las diferencias que existen entre el «Reglamento» y las propuestas de $\operatorname{Pradt}^{13}$. Y así lo corroboran también las objeciones del clérigo riojano al proyecto de reforma que envió Azanza al rey (13-12-1809) o «plan general del clero» ${ }^{14}$, copia casi literal en algunos casos del plan que comentamos $^{15}$. Sí es cierto, por el contrario, que Llorente fue el ejecutor y beneficiario a la vez de la política religiosa de José I, inspirada sin ninguna duda en el informe de Pradt. Nombrado, en efecto, Director General de Bienes Nacionales, cargo que ocupó hasta septiembre de 1810, no dudó en adquirir propiedades enajenadas al clero regular ${ }^{16}$, siguiendo fielmente el ejemplo de otros políticos afrancesados ${ }^{17}$.

Pese a que no disponemos de datos suficientes, no descartamos que entre los colaboradores de Pradt se hallaran también algunos otros eclesiásticos muy adictos desde el primer momento a la nueva dinastía, tales como Ramón José de Arce y Pedro de Estala. El primero de ellos, arzobispo de Zaragoza y patriarca

${ }^{11}$ F. FernÁNDEZ (editor), Juan Antonio Llorente, español «maldito», San Sebastián, 2001, pp. 566 ss. Para el conocimiento de la personalidad del coronel Amorós remito a la reciente y documentada biografía de R. FERNÁNDEZ, Francisco Amorós y los inicios de la educación física moderna, Alicante, 2005 .

12 El «Reglamento» de Llorente se conserva en los Archivos Nacionales de París (AF IV 1609), pièce 294. Ha sido analizado por diversos autores, entre ellos el hispanista G. Dufour, Juan Antonio Llorente en France, Ginebra, 1982, pp. 19-20; F. FERNÁNDEZ, op . cit., pp. 435-438.

${ }^{13}$ Las principales discrepancias radican en lo siguiente: Llorente era partidario acérrimo de mantener el diezmo; de suprimir paulatinamente el clero regular, manteniendo el «clero episcopal y parroquial»; sin proponer en absoluto el modo de financiar al clero suprimido, al tiempo que establecía un mapa eclesiástico acorde con la nueva organización territorial civil y militar, y muy distinto del que se recogía en el plan.

14 Gaceta de Madrid de 1 de diciembre de 1810.

15 Cf. F. FERnÁnDEZ, op. cit., pp. 542-544. El documento relativo al informe de Azanza se encuentra en los Papeles de Llorente. La política religiosa de José I ha sido analizada de manera sustancial por J. MERCADER en su obra de referencia José Bonaparte, rey de España, 1808-1813. Estructura del Estado español bonapartista, capítulo XIII, Madrid, 1983. Completaba así sus aportaciones anteriores en su primer volumen titulado José Bonaparte, rey de España, 1808-1813. Historia externa del reinado, capítulo II, Madrid, 1971.

16 Juan Mercader RiBA, «La desamortización en la España de José Bonaparte», Hispania, 122 (sep. -diciembre de 1972) 604.

17 Ibidem, pp. 602 ss. 
de las Indias, era un gran conocedor de los entresijos del clero español, habiendo sido nombrado al igual que Llorente, consejero de Estado; fue elevado al cargo de capellán mayor del rey, muy probablemente por su vinculación a la francmasonería española de la que José I era Gran Maestre. Pedro de Estala era canónigo de la catedral de Toledo, siendo considerado muy pronto como una de las mejores plumas del régimen; fue autor de un opúsculo laudatorio, titulado «Reflexiones imparciales sobre el estado actual de España», publicado en Vitoria el 8 de septiembre de 1808 .

El plan de reforma elaborado por Pradt era a todas luces mucho más radical que el «Reglamento» de Llorente y, desde luego, mucho más audaz y polémico que el que se aprobó en Cádiz, bastante racional y circunspecto ${ }^{18}$. Con él se trataba en rigor de implantar en España la reforma eclesiástica francesa, fruto del cesarismo revolucionario de Napoleón, orientado a convertir al clero en actor social y colaborador político del régimen bonapartista. Inspirado en la Constitución Civil del Clero ${ }^{19}$ y en el Concordato de 15 de julio de 1801, hacía también suyos los postulados esenciales de ambos documentos.

Al igual que la Constitución Civil del Clero, este plan nacía de una doble exigencia: la de proveer a la remuneración del clero una vez suprimidos los diezmos y expropiados sus bienes; y la de racionalizar la distribución geográfica de las diócesis y parroquias, para adaptarlas a las circunscripciones administrativas. Del Concordato y de los «77 artículos orgánicos», añadidos unilateralmente por Napoleón, recogía a su vez sus logros principales: la supremacía del poder civil sobre la Iglesia, la transformación de los ministros del culto en funcionarios y, aunque de modo implícito, el laicismo del Estado ${ }^{20}$.

Como en ambos documentos, también en el plan de reforma emergen las raíces teológicas y filosóficas de las que todos ellos se nutrían: el galicanismo más primigenio, el episcopalismo, el jansenismo y el utilitarismo. En particular, de este último, algunos de cuyos ideólogos (Holbach, Helvetius, Bentham y Destutt de Tracy, entre otros) influyeron considerablemente en los círculos intelectuales franceses a finales del siglo XVIII, e influirían más tarde de modo decisivo en el primer liberalismo español.

\footnotetext{
18 E. LA PARRA, El primer liberalismo y la Iglesia..., cit., pp. 67-171.

${ }^{19}$ En torno a la Constitución Civil del Clero, véase A. MATthiEz, La Revolución Francesa, Barcelona, 1935, I, pp. 173 ss.; F. J. Montalbán, Historia de la Iglesia Católica. Edad Moderna, Madrid, 1963, IV, pp. 370-374.

20 J. GODECHOT, Europa y América en la época napoleónica, Barcelona, 1976, pp. 22-26; J. LORTZ, Historia de la Iglesia, Madrid, 1962, pp. 556-559. El artículo primero del Concordato francés decía textualmente: «La religion catholique, apostolique et romaine sera librement exercée en France. Son culte sera public, en se conformant aux règlements de police que le gouvernement jugera nécessaire pour la tranquillité publique» (Citado por T. LENTZ, Nouvelle Histoire du Premier Empire, III, La France et l'Europe de Napoléon, 1804-1814, Paris, 2007, p. 246).
}

Hispania Sacra, LX

121, enero-junio 2008, 267-295, ISSN: 0018-215-X 
A partir, pues, de los principios utilitaristas, tanto la religión como los ministros del culto son contemplados exclusivamente en su dimensión social, en cuanto son o no útiles a la sociedad, estableciéndose una estrecha dependencia de la religión respecto a la sociedad. No sorprende, en consecuencia, que los autores del plan censuraran sin ambages el excesivo número de eclesiásticos considerados inactivos, la profusión de fiestas y ceremonias religiosas y, ante todo, la práctica del clero de convertir la religión en un puro espiritualismo, alejándola del interés social21.

De acuerdo con los antecedentes e ideales que hemos descrito, el plan de reforma eclesiástica se concretaba en los siguientes puntos: necesidad de una reforma «general y simultánea» del clero, tras un análisis previo de su situación real; reducción del número de eclesiásticos, en particular del clero considerado inactivo; abolición del diezmo y desamortización de los bienes del clero suprimido; un nuevo sistema de financiación de la Iglesia española; nueva organización territorial de las diócesis y parroquias; creación de una Escuela de Predicación; y necesidad de un Concordato con la Santa Sede.

\section{RASGOS GENERALES DEL CLERO ESPAÑOL}

El número de eclesiásticos en España, según se recoge en el informe de Pradt, ascendía a comienzos del siglo XIX a 149.373 individuos para una población aproximada de 11 millones de habitantes; una proporción muy superior a la de Francia en vísperas de la Revolución, con 159.936 eclesiásticos, y una población de 25 millones 22 . Se trata de una cifra aproximativa y no rigurosamente estadística, que serviría de base a la reforma que pretendía llevarse a cabo, pero que en cualquier caso era más realista que la proporcionada por el censo de Godoy realizado en 1797; en él se daba la suma de 148.409 eclesiásticos, sin contar los ministros y servidores del culto, como sí recogía el plan mencionado.

Muy alta y desmesurada era también la cifra de eclesiásticos calificados como inactivos frente a los activos o con cura de almas. Mientras estos últimos

${ }^{21}$ AN. 381 AP, leg. 17. Chapitre Premier: Etat du Clergé d'Espagne et nécéssité d'une reforme Générale et simultanée. «(...) Le Clergé d’Espagne ne voit dans la Religion que la Misticité, la Spiritualité Pure, et les pratiques religieuses avec les quelles il a materialisé, pour ainsi dire, la Religion (...). La societé ne s'occupe pas de la Religion dans ses rapports purement spirituels et mistiques, moins seulement dans ses rapports moraux en tant qu'ils l'atteignent dans ses interets (...). Elle a par conséquent le Droit de veiller sur la Religion, de la ramener à ces principes: ce n'est pas en vue du Ciel seulement que la société accorde des avantages temporels à la Religion et à ses Ministres (...). De leur coté le devoir de ceux-ci est de ramener sans cesse la Religion de la spiritualité a l'ordre social (...)».

${ }^{22}$ Chapitre second: Dénombrement du Clergé espagnol; Tableau Premier: Dénombrement du Clergé espagnol. 
(párrocos y vicarios) llegaban apenas a los 30.000 individuos, los primeros (monjes, frailes, religiosas, canónigos y beneficiados) alcanzaban la cifra de 111.000, es decir, las tres cuartas partes del clero español ${ }^{23}$. No es extraño, como se subraya en el informe, que el número excesivo de eclesiásticos hubiera fomentado la ociosidad, especialmente entre los frailes, incrementándose además de modo extraordinario las prácticas y ceremonias religiosas.

En el orden jurídico, la legislación relativa al clero era un manantial inagotable de procesos, al haberse convertido el derecho canónico español en un cúmulo de decretales, leyes antiguas y cánones de origen inmemorial. Casi en ningún caso el eclesiástico español estaba sujeto a la justicia ordinaria o a los tribunales civiles. Por otro lado, las exenciones de la jurisdicción episcopal eran más comunes que en otros países católicos de Europa, de manera que la excepción constituía el derecho común.

Había obispados como León y Oviedo que no dependían de ningún arzobispo metropolitano. Algunas diócesis, entre ellas Zaragoza y Jaén, tenían varias catedrales donde se turnaban los miembros del capítulo en determinadas fechas del año. Casi todos los cabildos estaban exentos de la jurisdicción ordinaria. Por supuesto, todas las órdenes religiosas al igual que las órdenes militares religiosas y las eclesiásticas que dependían de ellas. Los curas, en una gran proporción, no eran nombrados por los obispos. Algunas abadesas, como la de las Huelgas, ejercían desde su ordenación todos los derechos episcopales.

Por lo que se refiere a la extracción social y a la formación del clero, en España raramente abrazaban el estado eclesiástico los hijos de familias distinguidas o acomodadas, o pertenecientes al comercio o a las profesiones liberales, como ocurría en Francia. Por el contrario, los eclesiásticos españoles provenían comúnmente de estratos sociales bajos, atraídos por las facilidades que les ofrecían las escuelas religiosas o merced a los servicios que podían prestar a eclesiásticos de rango superior. Casi todos ellos realizaban tareas serviles o vivían de las limosnas mientras hacían sus estudios, práctica también habitual entre los estudiantes españoles.

La formación eclesiástica era muy deficiente en su conjunto, fruto casi siempre de la permanencia de los alumnos en unos centros donde no podían escuchar más que sutilezas escolásticas o tradiciones anticuadas. Por eso, un eclesiástico formado de esta manera no podía ser más que un cuerpo peligroso para el soberano y un obstáculo para la sociedad, al alejarla de su objetivo principal. Con todo, en las filas del clero había también un gran número de individuos que sobresalían por sus grandes virtudes, su patriotismo y sus conocimientos, a menudo profundos ${ }^{24}$.

\footnotetext{
${ }^{23}$ Tableau Premier.

${ }^{24}$ Chapitre Premier. «(...) un trés grand nombre d'Ecésiastiques Espagnols est recomendable par de grandes vertus, du patriotisme et des connaissances souvent profondes (...)».

Hispania Sacra, LX

121, enero-junio 2008, 267-295, ISSN: 0018-215-X
} 
Para remediar el problema de la mala formación, y teniendo en cuenta que el ministerio de la palabra es la parte más digna e influyente del ministerio sacerdotal, el plan preveía crear en Madrid una Escuela de Predicación, orientada a «evitar las sutilezas, el misticismo y las fábulas, que constituían el estilo habitual de las homilías predicadas en España (...)». Frente a todo ello, se trataría de «ofrecer a los fieles unos sermones más ordenados en sus formas, más evangélicos y más acordes con los intereses de la sociedad (...)» 25 .

\section{Cuadro I. Censo del clero español}

\begin{tabular}{|l|c|}
\hline Arzobispos & 8 \\
\hline Obispos en la Península & 46 \\
\hline Obispos en Baleares & 3 \\
\hline Obispos en Canarias & 2 \\
\hline Canónigos de catedrales y colegiatas & 400 \\
\hline Párrocos & 20.080 \\
\hline Vicarios, capellanes y sacerdotes con o sin beneficio & 40.000 \\
\hline Monjes y frailes & 22.000 \\
\hline Religiosas & 15.834 \\
\hline Ministros y servidores de la Iglesia & 49.000 \\
\hline TOTAL & $\mathbf{1 4 9 . 3 7 3 2 6}$ \\
\hline
\end{tabular}

Especial importancia adquiere el análisis, algo genérico pero interesante, de los recursos de la Iglesia española, uno de los objetivos fundamentales de la reforma. La renta del clero se cifraba en más de 350 millones de reales anuales, provenientes del diezmo -la fuente principal de esta clase de recursos-, del arriendo de los bienes inmuebles, de los censos y de los derechos de estola, generalmente bien retribuidos ${ }^{27}$. Destaca la gran desigualdad de la riqueza entre los diversos obispados, abadías y cabildos, siendo especialmente llamativa la fortuna que poseían los titulares de las mitras de Toledo y Sevilla, así como los monasterios de El Escorial, El Paular y la Cartuja de Jerez ${ }^{28}$.

25 Chapitre neuvième: Formation du Clergé d'Espagne.

${ }^{26}$ Tableau Premier. Se trata de cifras muy semejantes a las recogidas en el censo de 1797 y superiores, sobre todo en lo que atañe al clero regular, a las elaboradas casi treinta años más tarde por la Real Junta Eclesiástica, recogidas por J. SAEZ, Datos sobre la Iglesia española contemporánea,17681868, Madrid, pp. 194 ss.

${ }^{27}$ Chapitre troisième: Des biens du Clergé en Espagne.

28 Chapitre Premier. 
En cuanto al valor de los bienes inmuebles, se calcula en más de $2.000 \mathrm{mi}-$ llones de reales el montante que podrían alcanzar las ventas correspondientes al clero regular, y ello a pesar de las circunstancias por las que atravesaba el país, y excluyendo a aquellos edificios que pudieran utilizarse como centros civiles y militares. En cuanto al diezmo eclesiástico, un impuesto que teóricamente gravaba el diez por cien de los productos cosechados, pero que en la práctica equivalía al menos al 25 por cien del producto neto ${ }^{29}$, se elevaba a no menos de 200 millones al año ${ }^{30}$. De esta cantidad, sin embargo, debían detraerse 54 millones que iban a parar a las arcas reales, y otros 25 millones que correspondían a los partícipes legos ${ }^{31}$.

\section{CUADRO II. Recursos económicos del clero español}

\begin{tabular}{|l|c|}
\hline Conceptos & Rentas (en reales) \\
\hline El diezmo y la primicia & 200.000 .000 \\
\hline Renta provenientes de la tierra & 50.000 .000 \\
\hline Arriendo de edificios urbanos & sin datos \\
\hline Censales & sin datos \\
\hline Estipendios de misas & $29.200 .000^{32}$ \\
\hline Derechos de estola & 70.000 .000 \\
\hline TOTAL & $\mathbf{3 4 9 . 2 0 0 . 0 0 0}$ \\
\hline
\end{tabular}

Anacrónica y poco racional seguía siendo, por otro lado, la organización territorial de las diócesis españolas - un total de 59 obispados- y de las parroquias. Entre los defectos más notables sobresalía el desequilibrio geográfico de los obispados, contrastando vivamente la extensión de algunos de ellos con la pequeñez de otros. Diócesis como la de Toledo abarcaba tierras que iban desde Castilla la Vieja hasta Extremadura, la Mancha y Andalucía. La de Santiago, la

${ }^{29}$ L. BARBAStro, El clero valenciano..., cit., pp. 55 ss.

${ }^{30}$ Pese a las elevadas cifras que se dieron en aquellos años sobre el diezmo, consideramos a ésta como muy razonable, bastante similar a la que ofrece Artola, estimada en 279 millones en 1801 (Apud M. ARTOLA, La burguesía revolucionaria (1808-1874), en Historia de España Alfaguara, Madrid, 1974, V, p. 137; y casi idéntica a la que indicó el obispo Fraile en las Cortes del Trienio, de 211 millones (Apud M. Revuelta, Política religiosa..., cit., p. 30).

${ }^{31}$ Chapitre huitième: Comparaison de la somme des traitements et des pensions du Clergé...

${ }^{32}$ Se calcula que de los 109.000 sacerdotes que celebraban la misa diaria, unos 80.000 (cifra moderada) percibían estipendio, consistente en 1,3 reales.

${ }^{33}$ Chapitre troisième; y elaboración propia.

Hispania Sacra, LX

121, enero-junio 2008, 267-295, ISSN: 0018-215-X 
más extensa circunscripción metropolitana de la Península, contaba con 12 diócesis sufragáneas, entre ellas las tres de la región extremeña (Coria, Badajoz y Plasencia), completamente alejadas de la capital gallega.

Al mismo tiempo, ciudades como Madrid o Barcelona, cuyo desarrollo económico y demográfico era bien visible, carecía de sede episcopal la primera, mientras la segunda dependía del arzobispado de Tarragona, ciudad mucho menos avanzada que aquélla ${ }^{34}$. Otras, como Calahorra, Tarazona, Albarracín, Orihuela o Coria, convertidas a principios del siglo XIX en pueblos grandes, seguían manteniendo su categoría de sedes episcopales, en detrimento de otros núcleos urbanos emergentes y mucho más prósperos.

En cuanto a las parroquias, elemento básico en la organización administrativa de las diócesis, la cifra era de 20.080 en todo el país, una cantidad elevada y muy por encima de las necesidades del culto, a juicio de los autores del infor$\mathrm{me}^{35}$. Esta multiplicidad innecesaria de parroquias se registraba ante todo en las ciudades, de manera que como se ha escrito en nuestros días, aunque la sociedad española era eminentemente rural, la Iglesia era más bien urbana ${ }^{36}$. Una ciudad como Salamanca tenía 25 parroquias para 15.000 habitantes, y ello sin considerar el copioso número de conventos e iglesias allí existentes; Zamora a su vez contaba con 20 parroquias para 9.000 habitantes; y Toro, con otras 20 parroquias para 7.000 habitantes $^{37}$.

Este fenómeno se registraba en la mayoría de las ciudades, como lo demuestra el hecho de que, tomadas al azar 62 de ellas en todo el país, sumaban un total de 542 parroquias, esto es, 9 por cada una de las ciudades. Si tenemos en cuenta que la población total de ellas era de 936.400 habitantes, cada parroquia venía a tener sólo 1.727 feligreses ${ }^{38}$, una proporción muy inferior a la que debería corresponderle a cada una de ellas.

En el Cuadro III puede verse la distribución territorial de las diócesis españolas a comienzos del reinado josefino; en él se aprecian fácilmente algunos de los defectos a los que ya aludimos, en especial la extensa superficie de los arzobispados de Toledo, Santiago y Tarragona, con múltiples diócesis sufragáneas, algunas de ellas muy distantes de la metrópoli.

\footnotetext{
${ }^{34}$ Chapitre dixième: Nouvelle circonscription des Diocèses et de Curés.

35 Tableau Premier.

36 W. J. Callahan, op. cit., p. 18.

37 Chapitre dixième.

38 Ibidem.
} 
CuAdRo III. Circunscripción de las diócesis españolas en $1809^{39}$

\begin{tabular}{|l|l|}
\hline $\begin{array}{l}\text { Arzobispados } \\
\text { Metropolitanos }\end{array}$ & Diócesis sufragáneas \\
\hline Toledo & Cuenca, Sigüenza, Segovia, Osma, Valladolid, Córdoba, Jaén y Murcia \\
\hline Santiago & $\begin{array}{l}\text { Avila, Salamanca, Astorga, Zamora, Ciudad Rodrigo, Tuy, Orense, } \\
\text { Mondoñedo, Lugo, Coria, Plasencia y Badajoz }\end{array}$ \\
\hline Valencia & Segorbe y Orihuela \\
\hline Granada & Guadix, Almería y Ceuta \\
\hline Burgos & Pamplona, Tudela, Calahorra, Palencia y Santander \\
\hline Tarragona & $\begin{array}{l}\text { Barcelona, Gerona, Lérida, Vic, Tortosa, Seo de Urgel, Solsona, Mallorca, } \\
\text { Menorca e Ibiza }\end{array}$ \\
\hline Sevilla & Málaga, Cádiz y Canarias \\
\hline Zaragoza & Huesca, Barbastro, Jaca, Tarazona, Albarracín y Teruel.. \\
\hline Los obispados de León y Oviedo no dependen de ningún arzobispo metropolitano. \\
\hline
\end{tabular}

\section{ÁMBITOS ESPECÍFICOS DE LA REFORMA ECLESIÁSTICA}

Los aspectos afectados por la reforma son: reducción del número de eclesiásticos, supresión del diezmo y desamortización de los bienes eclesiásticos y financiación del clero por el Estado.

\section{Reducción del número de eclesiásticos}

El caballo de batalla de la reforma era, sin duda, la reducción drástica del número de clérigos, sobre todo de aquellos considerados inactivos. Una medida quirúrgica, si se tiene en cuenta los defectos que se les achacaba, y los objetivos específicos de esta reforma. En puridad, la revolución que Napoleón soñaba realizar en España tenía en la reforma del clero la clave de bóveda; o, si se quiere, era la condición indispensable de la misma «por ser el clero el origen del atraso de todo tipo que sufre la nación (...), de la degradación del espíritu público (...), y (por ser) un gran obstáculo para la felicidad y el avance de las Luces $(\ldots) »^{40}$.

${ }^{39}$ Neuvième Tableau: Ancien Circonscription des Diocèses; y elaboración propia.

${ }^{40}$ Chapitre Premier.

Hispania Sacra, LX

121, enero-junio 2008, 267-295, ISSN: 0018-215-X 
La reducción de miembros pertenecientes al clero regular era una de las prioridades de la reforma, una vez descartada la conveniencia de mantener algunos conventos. En todo momento prevalece la idea de que tales cenobios no son más que «focos de descontento político y de oscuridad para el espíritu humano». Menos importante parecía ser la reducción del clero secular, afectando sobre todo a algunos obispos y a los párrocos, tras la reorganización de las diócesis y parroquias; también se consideraba necesaria la reducción de canónigos y beneficiados, pues era muy abultada la cifra de capitulares en cada una de las catedrales y colegiatas. Según un estudio reciente, sólo el cabildo zaragozano, el más numeroso de España, contaba ya con una plantilla de 149 individuos, la mitad de ellos dignidades y canónigos.

Por todos estos antecedentes, el plan de reforma fijaba en 75.131 los eclesiásticos suprimidos, todos ellos con derecho a una pensión. Lo que significa que el número de clérigos para todo el país se limitaba a 74.242 individuos, es decir, menos de la mitad de los que había en 1809. Esta supresión alcanzaba de lleno a los religiosos y religiosas, como cabía esperar dada la opinión que se tenía acerca del clero regular en su conjunto; también, aunque en menor medida, afectaba a los cabildos catedralicios, al reducirse a sólo 12 el número de capitulares por cada uno de ellos; y finalmente a los párrocos y vicarios, al reorganizase el mapa de las parroquias. Subsistía, sin embargo, la mayoría de los vicarios o tenientes de cura, al igual que un determinado número de capellanes y beneficiados, aunque sin depender en ningún caso de las finanzas del Estado, como explicamos más tarde (CUADRO IV).

CUADRO IV. Reducción del número de eclesiásticos

\begin{tabular}{|l|c|}
\hline Obispos & 10 \\
\hline Canónigos & 1121 \\
\hline Religiosos & 40.000 \\
\hline Religiosas & 20.000 \\
\hline Párrocos & 4.000 \\
\hline Otros eclesiásticos & 10.000 \\
\hline TOTAL & $\mathbf{7 5 . 1 3 1 ^ { 4 1 }}$ \\
\hline
\end{tabular}

${ }^{41}$ Cinquième Tableau: Pensions du Clergé supprimé. 
Supresión del diezmo y desamortización de los bienes eclesiásticos

Como ya adelantamos al comienzo de este trabajo, los dos grandes objetivos del plan de reforma impulsado por Napoleón eran la abolición del diezmo y la venta de los bienes eclesiásticos, unas medidas que debían llevarse a cabo simultáneamente. Con ello se buscaba desmantelar la estructura económica de la Iglesia española, debilitando su influencia, y reforzar el poder del Estado y de la sociedad. Se trataba de un proyecto arriesgado y difícil, dada la compleja organización jurídica y económica de la Iglesia, en particular del diezmo, su principal fuente de ingresos. Por eso no sorprende que se opusieran sistemáticamente a la supresión de este impuesto los consejeros de José I, entre ellos Llorente. Bien es verdad que llevados más por la inercia y el temor a posibles revueltas del clero, que por maduros y sólidos razonamientos.

Para los autores del plan, la abolición del diezmo era la operación más idónea para conseguir sus propósitos, no sólo en lo que respecta a la Iglesia, sino sobre todo en relación a los fines económicos y sociales que podían derivarse de ella. En un análisis pormenorizado de sus grandes ventajas, se ponía especial énfasis en las siguientes: la disponibilidad de abundantes recursos para la economía, maltrecha entre otras causas por el déficit de la Deuda, la crisis del comercio ultramarino, las pérdidas internas y el aumento de la población; la posibilidad de establecer en adelante un único impuesto rústico, beneficiando con ello a los agricultores, teniendo en cuenta el elevado valor bruto del diezmo que estimaban en 2.000 millones de reales; y el hecho de poder impulsar en lo sucesivo el desarrollo de la agricultura, elevando al mismo tiempo el valor real de la propiedad rústica, frenados ambos por la pervivencia del diezmo.

Unos beneficios, en suma, que derivaban todos ellos de la aplicación de unas teorías económicas de carácter fisiocrático y a la par liberal, las mismas que pocos años más tarde impulsarían también las medidas económicas de los liberales españoles en la primera mitad del siglo XIX. He aquí algunos de los términos con los que justificaban esta medida los autores del plan:

(...) Con la abolición del diezmo, el nuevo Gobierno ofrece a toda la Nación el obsequio más preciado, capaz de aliviar sus pérdidas, ganar su afecto y elevar el valor de la propiedad. La supresión del diezmo, en fin, fortalecerá la propiedad en España, pues no puede considerarse verdaderamente dueño el que está obligado a dar eternamente la $6^{\text {a }}$ parte de la propiedad $(\ldots)^{42}$.

También la venta de los bienes del clero suprimido era una medida necesaria. Sus logros, tanto económicos como financieros e incluso sociales eran muy

\footnotetext{
${ }^{42}$ Chapitre quatrième:Nécéssité de l'abolition de la Dixme, de la vente des biens du Clergé et d'un nouvel ordre d'entretien pour le Clergé.

Hispania Sacra, LX

121, enero-junio 2008, 267-295, ISSN: 0018-215-X
} 
diversos: creación de un Fondo de Amortización; disponer de una gran masa de capitales susceptible de salir al mercado o de invertirse en obras públicas, potenciando de este modo la idea de nación; granjearse el apoyo al gobierno por parte de los nuevos compradores, como había sucedido en Francia; y, sobre todo, erradicar definitivamente los dos grandes vicios de la propiedad rústica en España: las «manos muertas» y la gran propiedad, multiplicando en adelante el número de cultivadores y, consecuentemente, favoreciendo el crecimiento agrícola ${ }^{43}$. Estos mismos fines, conviene recordarlo, estarán muy presentes en los decretos desamortizadores de Mendizábal y Madoz, como lo habían estado antes en los del Trienio, periodo que no ha sido suficientemente investigado y valorado en su dimensión económica.

\section{Financiación del clero por el Estado}

Una vez eliminadas las fuentes de riqueza del clero con la supresión del diezmo y la venta de una gran parte de sus bienes, el Estado se erigía en el único garante de su subsistencia. Era lo lógico en unas circunstancias como las de España, un país de tradición católica, a comienzos del siglo XIX. Pero, sobre todo, era lo que pretendía verdaderamente el nuevo sistema político, ya que a través de un salario podía atraerse al clero por el lado más sensible de sus intereses, impidiendo su independencia y limitando su poder en la sociedad ${ }^{44}$.

Un salario, y no el diezmo o una parte del diezmo como medio de financiar al clero. Esta fue la fórmula que se impuso frente a quienes defendían la supervivencia del diezmo administrado por el gobierno o por los propios párrocos, como proponía Llorente. A las razones ya expuestas acerca de la supresión total del diezmo se añadían ahora algunas otras, tales como las dificultades que acarrearía una administración general del mismo, y que estaban relacionadas con diferentes asuntos (cantidad a percibir por cada eclesiástico, diversidad geográfica de los perceptores, el elevado número de empleados, etc.). Por lo demás, aun en el caso de que se admitiera esa administración general, «¿qué más le daba al clero español ser pagado con el producto decimal que con los fondos del Tesoro Público?» ${ }^{45}$.

\footnotetext{
${ }^{43}$ Ibidem. Con el capital proveniente de las ventas se preveía dedicar la décima, duodécima y décimo quinta parte del mismo a sufragar los gastos de las obras públicas (puentes, caminos, canales de navegación, riegos, puertos y otras de interés nacional). Chapitre douzième: Bases du nouvel ordre Eclesiastique en Espagne.

${ }^{44}$ Chapitre cinquième: Nécéssité de salarier le Clergé. «(...) Mais la raison péremptoir de l'assujetissement du Clergé à un traitement provenant du Trésor Public, est la nécéssité absolue de s'attacher le Clergé pour le Lien le plus sensible de (tous) de son interêt (...). Avec de la Dîme, et des propriétés, le Clergé conservera de l'independance (...). La politique du souverain de l'Espagne doit tendre sans cesse à diminuir l'influence de son Clergé, à maîtriser cette influence (...)».

45 Ibidem.
} 
El salario para los eclesiásticos activos, y una pensión para el clero suprimido serían, pues, en adelante las formas de subvencionar a la Iglesia, una vez puesta en marcha la reforma. La cantidad que se asignaba a los primeros ascendía a algo más de 29,5 millones de reales anuales. Ese salario, como podrá verse, no era igual para todos, con el fin de favorecer el estímulo entre los distintos eclesiásticos, y por entender que «frecuentemente, nada es más desigual que una rigurosa igualdad» ${ }^{46}$. De ahí que fuera diferente al tratarse de los obispos, canónigos y párrocos en función de los lugares en donde ejercían su ministerio.

CUADRo V. Presupuesto destinado al clero activo

\begin{tabular}{|l|c|c|}
\hline Instituciones & Retribución (en rls.) & Totales (en rls.) \\
\hline Arzopispado de Madrid & 120.000 & \\
\hline Id. Barcelona & 100.000 & \\
\hline Id. Sevilla & 100.000 & \\
\hline Id. Valencia & 80.000 & \\
\hline Id. Zaragoza & 80.000 & \\
\hline Id. Granada & 60.000 & \\
\hline Id. Santiago & 50.000 & 640.000 \\
\hline Id. Burgos & 50.000 & 1.400 .000 \\
\hline OBISPADOS & & 150.000 \\
\hline 35 obispos en la Península ${ }^{47}$ & 40.000 cada uno & \\
\hline 5 obispos auxiliares & 30.000 cada uno & \\
\hline CABILDOS & & 240.000 \\
\hline 48 cabildos con 12 canónigos & 2500 cada uno & \\
\hline 96 de las metropolitanas & 2000 cada uno & \\
\hline 480 catedrales sufragáneas & & 24.0000 \\
\hline PARROQUIAS & 1500 cada uno & 1.080 .000 \\
\hline 16.000 párrocos & & 24.000 \\
\hline SEMINARIOS DIOCESANOS & TOTAL & \\
\hline 45 & & \\
\hline CASAS DE RETIRO & & \\
\hline 45 & & \\
\hline & & \\
\hline
\end{tabular}

${ }^{46}$ Chapitre sixième: Du traitement du Clergé.

${ }^{47}$ Erróneamente se computa un obispado menos de los existentes en la Península tras la nueva organización territorial.

${ }^{48}$ Quatrième Tableau: Traitement du Clergé Espagnol activ; y elaboración propia.

Hispania Sacra, LX

121, enero-junio 2008, 267-295, ISSN: 0018-215-X 
El rey, por su parte, se reservaba un número determinado de beneficios (51 en total) de diferente cuantía, capitalizados en 600.000 reales $^{49}$. Con ellos se trataría de recompensar a aquellos eclesiásticos que destacaran por sus virtudes, talentos o servicios. La Escuela de Predicación, encargada de formar a los ministros de la palabra, como ya explicamos, sería financiada también por el gobierno, asignándole una dotación particular en inmuebles. El gasto anual se fijaba en 40.000 reales $^{50}$. Los vicarios parroquiales dependerían en adelante de los ayuntamientos respectivos, como sucedía en Francia, compartiendo a su vez con los párrocos los derechos de pie de altar o de estola. Nada se dice en el plan acerca de la financiación de los capellanes y beneficiados que no habían sido suprimidos. Lógicamente cabe pensar que dependerían, como antes, de sus respectivas capellanías y prebendas.

CuAdro VI. Pensión del clero suprimido

\begin{tabular}{|l|c|c|}
\hline Perceptores & Cantidades & Totales $($ en rls.) \\
\hline 10 obispos & 10.000 cada uno & 100.000 \\
\hline 1121 canónigo & 500 cada uno & 560.500 \\
\hline 40.000 religiosos & 500 cada uno & 20.000 .000 \\
\hline 4000 párrocos & 500 cada uno & 2.000 .000 \\
\hline 20.000 religiosas & 300 cada una & 6.000 .000 \\
\hline 10.000 eclesiásticos inferiores & 300 cada uno & 3.000 \\
\hline TOTAL & & $\mathbf{3 1 . 6 6 0 . 5 0 0} \mathbf{s}^{5}$ \\
\hline
\end{tabular}

Por lo que se refiere a las pensiones, el Tesoro Público debía pagar al clero suprimido entre 31,6 y 37.8 millones de reales al año. Estas pensiones estaban reguladas de modo uniforme, estableciendo solamente tres escalas diferentes: la de los obispos, que cobrarían 10.000 reales cada uno; la de los canónigos, párrocos y religiosos, que percibirían entre 500 y 750 reales cada uno; y la de las religiosas y otros eclesiásticos, que cobrarían entre 300 y 400 reales cada uno de ellos ${ }^{52}$. Eran, como puede apreciarse, pensiones muy bajas, insuficientes en su mayor parte para sobrevivir sin contar con otros recursos. Pero se lograba así

\footnotetext{
${ }^{49}$ Huitième Tableau: Bénéfices à la disposition du Roi.

50 Chapitre neuvième: Formation du Clergé d'Espagne.

51 Cinquième Tableau; y elaboración propia. En otro presupuesto se elevaba la suma total a 37,8 millones de reales al retribuir mayores cantidades a los distintos beneficiarios.

${ }^{52}$ Cinquième, et sixième Tableau: Pension du Clergé suprimé.
} 
no gravar excesivamente al erario -de hecho apenas se superaban los 70 millones anuales destinados a culto y clero-, y se aseguraba en el futuro esa paga, por módica que fuere ${ }^{53}$. En definitiva, el plan de reforma ponía fin, por un lado, a las escandalosas diferencias económicas que habían existido hasta ahora en el clero, pero al mismo tiempo abría las puertas de la indigencia o la miseria a un número nada despreciable de sus miembros.

\section{Nueva organización territorial de la Iglesia española}

El plan de reforma venía también, como era lógico, a corregir las deficiencias que había en la organización territorial de las diócesis españolas, la misma prácticamente desde hacía varios siglos. Por eso, los cambios que debían producirse iban en la siguiente dirección: corregir las grandes desigualdades geográficas de los obispados; tratar de acercar las sedes episcopales a los diocesanos; disminuir su número en aquellos lugares donde eran excesivas; erigir nuevas sedes donde eran necesarias; y, por supuesto, confeccionar un nuevo mapa eclesiástico teniendo como ejes fundamentales a los arzobispados metropolitanos, un total de ocho, procurando que las diócesis sufragáneas estuvieran más cercanas, o tuvieran estrechas relaciones con aquellos.

De acuerdo con estos criterios, el nuevo mapa estaría formado por 8 arzobispados y 41 diócesis sufragáneas, es, decir, 10 diócesis menos que en la anterior circunscripción. Entre los arzobispados o metrópolis se hallaban: Madrid, sede de nueva creación, que sustituía a la de Toledo; Barcelona, en lugar de Tarragona; y los arzobispados de Sevilla, Valencia, Zaragoza, Granada, Santiago y Burgos. En cuanto a las diócesis sufragáneas, se suprimían 16 de las existentes hasta ahora, y se creaban otras seis. Las diócesis suprimidas eran las siguientes: Vic, Lérida y Tortosa, en Cataluña; Tudela, en Navarra; Tarazona, Huesca, Barbastro y Albarracín, en Aragón; Calahorra, en la Rioja; Palencia y Zamora, en Castilla; Coria y Badajoz, en Extremadura; Tuy y Lugo, en Galicia; Orihuela, en tierras valencianas. Las diócesis de nueva creación eran éstas: Mérida, en Extremadura; Ciudad Real, en la Mancha; Calatayud, en Aragón; Cartagena en la región de Murcia; Soria, en Castilla, sustituyendo a Osma; y Vitoria, en las Vascongadas ${ }^{54}$.

Los obispados de León y Oviedo, que hasta ahora eran exentos, pasaban a la jurisdicción de Santiago, sede metropolitana en donde las diócesis sufragáneas se reducían a cinco. Las tres diócesis de las Baleares, adscritas antes al arzobispado de Tarragona, pasarían a depender del arzobispado de Valencia. De este

\footnotetext{
${ }^{53}$ Chapitre septième: Pension du Clergé suprimé.

${ }^{54}$ Chapitre dixième: Nouvelle Circonscription des Diocèses et des Curés.
} 
modo, con la nueva reestructuración de las diócesis, a cada una le corresponderían unos 225.000 habitantes, en lugar de los 150.000 que les pertenecían en la anterior circunscripción ${ }^{55}$.

Frente a la antigua organización territorial, si bien se mantenía el número de sedes episcopales en las capitales de provincia, 34 en total, se reducía considerablemente el de aquellas ciudades que no eran capitales de provincia: 15 diócesis frente a las 24 anteriores. Por otro lado, se erigían nuevas sedes coincidiendo con las circunscripciones civiles, como Madrid, convertida en metrópoli, que a su vez contaría con diez obispados sufragáneos; Mérida, que sustituía a Badajoz; Ciudad Real, jurisdicción hasta ahora de las órdenes militares; Vitoria, desgajada de la diócesis de Calahorra, y la única en las Vascongadas; y Soria, en lugar de Osma. Un mapa mucho más acorde, desde luego, con la administración civil, que contaba también con 49 provincias en 1809, y mucho más en consonancia con la dinámica socio-económica del país.

CUADRO VII. El nuevo mapa eclesiático

\begin{tabular}{|l|l|}
\hline Arzobispados & Diócesis sufragáneas \\
\hline Madrid & $\begin{array}{l}\text { Segovia, Salamanca, Avila, Ciudad Rodrigo,Plasencia, Mérida, Toledo, } \\
\text { Ciudad Real, Cuenca y Sigüenza. }\end{array}$ \\
\hline Granada & Guadix, Almería y Jaén. \\
\hline Sevilla & Cádiz, Málaga, Córdoba, Ceuta y Canarias. \\
\hline Burgos & Vitoria, Santander, Valladolid, Pamplona y Soria \\
\hline Santiago & Astorga, León, Mondoñedo, Orense y Oviedo. \\
\hline Valencia & Segorbe, Murcia, Cartagena, Mallorca, Menorca e Ibiza \\
\hline Barcelona & Tarragona, Gerona, Solsona y Seo de Urgel \\
\hline Zaragoza & Teruel, Calatayud y Jaca ${ }^{56}$. \\
\hline
\end{tabular}

También el mapa de las parroquias sería modificado con el nuevo plan. Su número, un total de 20.080 , se reduciría a 16.000 . Esta reducción afectaba muy especialmente a las ciudades, donde la cifra era muy elevada, como vimos, y en mucha menor medida a los núcleos rurales, tratándose de regiones más pobladas como las de Levante y Andalucía. A partir del estudio realizado en una gran

\footnotetext{
55 Ibidem.

56 Dixième Tableau: Nouvelle circonscription des Diocèses.
} 
parte de las ciudades españolas por los mismos autores del plan, al que nos referimos en otro lugar, y asignando la cifra de 8.975 habitantes a cada una de las demarcaciones parroquiales, se llegaba a la conclusión de que la cantidad adecuada de parroquias para atender decorosamente el culto no debía exceder de las 15.000 a las 16.000 en todo el país.

Haciendo especial hincapié en el modelo de parroquia urbana, en el que se centraba singularmente el plan de reforma, se ponía de manifiesto que la experiencia había demostrado que las parroquias grandes solían ser siempre las mejor administradas y las que contaban con los mejores sacerdotes. En contraposición a las pequeñas, sometidas frecuentemente a la estrechez de miras, a la envidia y a las rivalidades entre los miembros del clero de una misma ciudad ${ }^{57}$. Y tomando como referencia a la ciudad de París, se argüía que no se podían comparar en modo alguno la administración y la excelencia del clero de las parroquias grandes con las de las pequeñas. Paradigma de las primeras era, sin ninguna duda, la parroquia de San Sulpicio, la más grande del mundo ${ }^{58}$.

No podía faltar entre las bases de la reforma la que se refiere al poder jurisdiccional de los obispos, tan debilitado en muchos casos por la exención de que gozaban determinadas instituciones y cuerpos eclesiásticos. Sin hacer ninguna alusión teórica al carácter de la autoridad episcopal, los autores del plan se limitaban a establecer simplemente algunas medidas concretas para fortalecerla. Todas ellas derivaban de un principio básico: «toda jurisdicción exenta del obispo queda suprimida». En consecuencia, ningún eclesiástico podría ejercer sus funciones sin la autorización del ordinario; los canónigos de las catedrales al igual que los curas párrocos serían nombrados por el obispo; los seminarios quedaban bajo la supervisión de éste, al igual que los superiores designados por él. Al obispo, en fin, correspondía escoger a los eclesiásticos que debían ser admitidos en la Escuela de Predicación, y a quienes hubieran de percibir una pensión por jubilación o retiro ${ }^{59}$.

\section{EL CONCORDATO ¿UNA MERA FORMALIDAD JURÍDICA?}

La transacción con la Santa Sede en relación a las medidas de reforma eclesiástica prevista era considerada por los autores del plan como un requisito indispensable. Así parecían exigirlo, en primer lugar, las circunstancias históricas de un país católico como España, cuyos monarcas habían hecho uso de esta fórmula concordataria. Así lo pedía también el sentido práctico, tratando de evitar

\footnotetext{
57 Chapitre dixième.

58 Ibidem.

${ }^{59}$ Chapitre douxième: Bases du nouvel ordre Eclesiastique en Espagne.
} 
en el futuro posibles contratiempos que se derivarían si se omitía este requisito. Y así lo reclamaba, en fin, la propia envergadura de la reforma. Sin embargo, según todos los indicios, este necesario consenso no nacía de un deseo sincero de llegar a un acuerdo con el Papa, opuesto taxativamente por lo demás a este tipo de medidas. Se trataba más bien de un plan preconcebido, plasmado con el firme propósito de llevarlo a cabo cuanto antes, utilizando para ello una hábil pero firme estrategia del gobierno josefino ante la Santa Sede.

En el fondo, en la ejecución de este plan de reforma se hallaba muy presente la experiencia diplomática del gobierno francés durante el Consulado, que tan excelentes resultados había cosechado con la firma del Concordato de 15 de julio de 1801. Las palabras que siguen desvelan en buena medida la verdadera intencionalidad de quienes, forzados ante todo por las circunstancias y por el temor a posibles disturbios, apelaban de manera sutil a la fórmula concordataria:

(...) Una vez que se hayan establecido y puestas en ejecución las bases de la reforma, pasarán a formar parte obligatoriamente del Concordato de España, como lo fueron las del Concordato francés (...). Estamos plenamente convencidos de que con una firmeza calculada y respetuosa lograremos atraernos a la Corte de Roma, haciéndole comprender que si los estados Católicos tienen necesidad de ella, también ella los necesita $(\ldots)^{60}$.

\section{CONCLUSIÓN}

En las páginas que preceden hemos intentado exponer las líneas maestras de la reforma de la Iglesia española recogida en el trabajo dirigido por el abate Pradt. Es menester incidir ahora algo más en algunos aspectos relevantes del mismo, destacando su alcance, valorando su trascendencia histórica y su viabilidad. En primer lugar, conviene recordar que este plan, hasta ahora desconocido e inédito, se inscribe en un contexto marcado intensamente por el ideario revolucionario de 1789, y responde en gran medida a la concepción del Estado y al proyecto cesarista de Napoleón en relación con la Iglesia Católica en los distintos países de Europa dominados por él.

Los redactores de este plan, eclesiásticos en su mayoría, fieles a un desaforado galicanismo avivado por el proyecto bonapartista pretendían en principio vincular a la Iglesia española al nuevo Estado, procurando que sus miembros

${ }^{60}$ Chapitre treizième: Du Concordat. «(...) Lors que las bases en auront été établies d'une manière invariable et qu'elles auront reçues leur éxécution, elles deviendront forcèment celles du Concordat d'Espagne, comme elles sont devenues celles du Cocordat de France (...). Avec une fermeté calculée et respectueuse, on est toujours sur de ramener la Cour de Rome et de finir par lui faire concevoir que si les etats Catholiques ont besoin d'elle, elle a aussi besoin d'eux (...)». 
contribuyeran decisivamente al progreso social. Al mismo tiempo, y de modo inconfundible, se intentaba crear lo que Thierry Lenz denomina una «Iglesia administrativa», refiriéndose al modelo de Iglesia francesa a partir del Consulado, con la existencia de un ministerio de Cultos, encargado de los asuntos religiosos del país y controlado por el gobierno ${ }^{61}$. No parece, desde luego, que con el nuevo plan se tratara de provocar en ningún caso una ruptura con la Iglesia Católica. Esto era algo inconcebible a comienzos del siglo XIX, contrario al texto del Estatuto de Bayona (art. $1^{\circ}$ ), de carácter confesional, e incluso al espíritu pragmático del Emperador respecto a la religión católica ${ }^{62}$, y perjudicial a la postre para los intereses del gobierno josefino por diversos motivos.

A nuestro juicio, una de las mayores aportaciones de este documento a la historia contemporánea estriba en haber afrontado con decisión y por primera vez la improrrogable reforma eclesiástica española, distinguiendo claramente las dos facetas sustanciales de la Iglesia Católica: la dimensión espiritual o interna, y la dimensión disciplinar o exterior, es decir, la Iglesia como institución u organización administrativa. Es a esta última, como lo había sido también en épocas pasadas, a la que se dirige de lleno la reforma, estableciendo ante todo unas nuevas bases socio-económicas, tras eliminar los tradicionales recursos del clero, en particular el diezmo. En modo alguno concernía a la moral y la fe católicas, de las que poco a casi nada se dice. En consecuencia, nos hallamos ante un plan de reforma de la Iglesia española, estrechamente relacionado con la estructura y la organización económica del nuevo tipo de Estado, incompatibles con el excesivo poder material y moral del clero, uno de los pilares esenciales del antiguo régimen, que a todo trance era preciso modificar.

No menos interesante nos parece el afloramiento a lo largo de este plan del conflicto político-eclesiástico, más que político-religioso, entre el nuevo gobierno y la Iglesia española; un claro precedente de la problemática religiosa surgida años más tarde con los gobiernos liberales, en particular durante el Trienio y el Sexenio, ambos de carácter radical y revolucionario. Conviene recordar que los forjadores de este tipo de reforma en Francia habían sido precisamente algunos de los prohombres de la Asamblea Constituyente, entre ellos eclesiásticos tan destacados como Sieyès, Talleyrand y Grègoire, o pensadores tan brillantes como Du Pont de Nemours, Garat, Roederer y, sobre todo, Destutt de Tracy, considerado por Napoleón como el jefe de los «ideólogos»; un grupo de gran relevancia histórica, relacionado en su mayor parte con el Institut des sciences et des arts de París, creado por la Constitución del Directorio. De este prestigioso centro académico surgirían algunos de los intelectuales hostiles a Napoleón, entre ellos no pocos de los que habían sido antes sus directos colabo-

${ }^{61}$ T. LENTZ, op. cit., p. 242.

62 Ibidem, p. 246.

Hispania Sacra, LX

121, enero-junio 2008, 267-295, ISSN: 0018-215-X 
radores, así como los principales teóricos del liberalismo francés y europeo: Juan Bautista Say y Benjamín Constant.

En consonancia con los principios de estos «ideólogos», creemos que tanto en la reforma eclesiástica francesa como en la que se pretendía llevar a cabo en España, se trazan ya las líneas de un proceso trascendental en la historia contemporánea que conocemos como secularización, y que tan fuertemente ha venido sacudiendo los cimientos de la Iglesia Católica. Pero una secularización entendida todavía en su sentido amplio, y no en cuanto significa un movimiento desacralizador y laicista, como el que hoy se extiende por los países de raíces judaico-cristianas; una secularización, en suma, que comporta un cambio socio-cultural en el que el hombre $\mathrm{y}$, por supuesto, los ministros del culto debían tomar conciencia de su papel en este mundo, de la misma manera que los gobiernos se preocupaban de emprender reformas fundadas en el orden natural, y orientadas al bien común.

Pero a este juicio esencialmente positivo acerca del informe de Pradt, hemos de contraponer algunas valoraciones de signo muy distinto. En primer lugar, en lo que atañe a la aplicación casi idéntica del modelo de reforma francesa a la Iglesia española. Ni la situación del clero era la misma, siendo a veces parcial y sesgado el juicio que sobre él ofrecen los autores de este plan; ni lo era tampoco la realidad social, económica y política de España con respecto a Francia. Sin olvidar la escasa importancia que se atribuye a la tradición histórica de la Iglesia española y de su clero, punto de partida y referencia obligada de una buena reforma.

En segundo lugar, y aun asumiendo la necesidad e incluso la urgencia de muchas de las medidas reformistas, este plan adolecía tanto en su origen como en sus planteamientos de un grave defecto: hacer caso omiso del carácter mixto de una gran parte de esas medidas, de manera que sólo podían ser abordadas razonablemente a través de un acuerdo con la autoridad eclesiástica. De esta índole eran precisamente los temas fundamentales de la reforma, como la jurisdicción episcopal, la supresión del clero regular, la reducción de miembros del clero secular y, por supuesto, la nueva configuración administrativa de las diócesis y parroquias.

En línea con lo que acabamos de exponer, no es menos censurable la contradicción en la que se incurría a la hora de poner en marcha la reforma. En efecto, mientras por un lado se consideraba necesario acudir a la transacción con el Papa, se adjudicaba en exclusiva a Napoleón esta difícil tarea, «por ser él quien había concebido la revolución en España, quien tenía en sus manos el poder de dominarla, y a quien correspondía establecer las nuevas instituciones, pudiendo usar la fuerza sin oposición alguna» ${ }^{63}$.

${ }^{63}$ Chapitre onzième: Nécessité que la réforme soit générale, et simultanée, et que les bases en soyent arrêtées par S.M. l'Empereur. 
Llevados de un irrefrenable afán adulador, los redactores del plan llegaban a convertir a Napoleón en el verdadero y exclusivo promotor de una reforma «que ataca y destruye la superstición hasta su último rincón, y que lo mostrará a toda Europa, en donde él ha extendido y consolidado la tolerancia, como el que condujo al clero europeo hasta la ilustración, tras haber sido el más alejado de ella» ${ }^{64}$. Sin ningún rubor no dudaban en subordinar la acción del gobierno de José I a los intereses y a la autoridad omnímoda del Emperador:

(...) Es a él a quien compete confeccionar el plan de la reforma. El rey de España lo completará más tarde (...). El conquistador de España no experimentará la oposición que el monarca español habría de sufrir incluso por parte de sus más fieles servidores (...). Puesto que las nuevas instituciones comportan siempre elementos dolorosos para los individuos, ¿no es una buena política encomendarlas a la autoridad pasajera, antes que a la que ha de permanecer?65.

De todo ello cabe concluir que la política religiosa promovida desde 1809 por el gobierno de José I y plasmada en diferentes medidas legislativas (supresión de regulares, reducción del personal eclesiástico, apoyo al clero parroquial y usurpación de la jurisdicción eclesiástica, entre otras ${ }^{66}$, no fue iniciativa del propio gobierno, sino una aplicación mimética de la reforma impulsada por $\mathrm{Na}$ poleón. De ahí, pues, que sea discutible la tesis de quienes han venido sosteniendo el carácter singular y específico de la reforma eclesiástica de este periodo y, sobre todo, el protagonismo que se ha atribuido al clero afrancesado en este importante asunto ${ }^{67}$.

Por lo demás, y en relación con el gobierno de José I Bonaparte, es evidente que carecemos todavía de un estudio exhaustivo y minucioso de su política religiosa y de sus verdaderas consecuencias. Pero no albergamos ninguna duda después del trabajo que presentamos de que en las actuaciones de dicho gobierno prevaleció a este respecto la radicalidad, y no la moderación y la prudencia, como se ha escrito recientemente ${ }^{68}$. Una radicalidad y un maximalismo, propios

64 Ibidem.

65 Ibidem. (...) C'est a lui seul à tracer le cadre. Le Souverain de l'Espagne le remplira ensuite (...). Le conquérant de l'Espagne n'éprouvera aucune des contradictions que le Roi d'Espagne éprouverait même de la part de ses plus dévoués serviteurs. Comme les nouvelles institutions emportent toujours avec elles quelque chose de douloureux pour les individus, n'est il pas de la bonne politique d'en charger l'autorité passagère, de préférence a celle qui doit rester? (...).

${ }^{66}$ M. Revuelta, La Iglesia española y el Antiguo Régimen..., cit., pp. 17-26.

67 VV.AA, El clero afrancesado, Aix-en-Provence, 1986. En esta obra se aborda nuevamente la vinculación de algunos eclesiásticos a la masonería por parte de J. A. FERRER BENIMELLI, autor de otros estudios relativos a la francmasonería en España durante el reinado josefino: «La Masonería bonapartista en España», en Les espagnols et Napoleón, Etudes Hispaniques, 7 (1984), 335-386; Masonería española contemporánea, 1808-1868, vol. I, Madrid, 1980, pp. 38-105.

68 J. LóPEZ TABAR, Los famosos traidores. Los afrancesados durante la crisis del Antiguo Régimen (1808-1833), Madrid, 2001, p. 87.

Hispania Sacra, LX

121, enero-junio 2008, 267-295, ISSN: 0018-215-X 
del modelo de reforma elaborado por Pradt e impulsado explícitamente por Napoleón, que si no llegaron a los niveles previstos fue debido a las gravísimas circunstancias por las que atravesaba el país, al freno establecido por algunos ministros y consejeros de Estado, al desarrollo de la guerra, de marchamo no sólo político sino «religioso» ${ }^{69}$, y al desenlace final de este azaroso periodo histórico.

Es innegable, por otro lado, que algunas de estas medidas de carácter revolucionario fueron atemperadas por el comportamiento prudente de determinados obispos. Esta fue, precisamente, la actitud de Fr. Miguel Suárez de Santander, obispo auxiliar desde 1803 de la diócesis de Zaragoza, y uno de los miembros más representativos del clero afrancesado; llevado de un espíritu conciliador trató de reducir los efectos del decreto de 18 de agosto de 1809 sobre la supresión del clero regular, logrando que sobrevivieran en la diócesis zaragozana algunos de los conventos afectados por la ley ${ }^{70}$.

Fueron los distintos factores antes mencionados, junto a los que indicaremos a continuación, los que contribuyeron poderosamente a hacer inviable el plan de reforma previsto. Entre estos últimos hay que subrayar la creciente hostilidad de la gran mayoría del clero regular, «los más fervientes emisarios de la oposición» en palabras del embajador francés, hacia el gobierno josefino y las medidas adoptadas, compartida también por una parte considerable del clero secular ${ }^{71}$. Una animadversión que se acrecentó sobre todo a partir del verano de 1809, jalonado en el exterior por acontecimientos tan llamativos e inquietantes como la invasión y anexión de los Estados pontificios por las tropas napoleónicas, la consiguiente excomunión del Emperador por Pío VII, el arresto y destierro de este último a Savona y más tarde a Fontainebleau; en suma, la ruptura de relaciones diplomáticas y la incomunicación del gobierno francés con la Santa Sede $^{72}$.

\footnotetext{
${ }^{69}$ El sustrato «religioso» de la Guerra de la Independencia ha sido subrayado por A. MOLINER PRADA, en su trabajo «La moderación de la revolución española de 1808», en Les Revolutions Ibériques et Ibéro-Américaines à l'aube du XIXe siècle, Paris, 1991, pp. 127-138.

70 L. Barbastro, Los afrancesados. Primera emigración política del siglo XIX español (18131820), Madrid, 1993, pp. 96-98. Pese a no existir todavía una monografía acerca de este personaje tan significativo, contamos sin embargo con valiosos estudios como el de A. ELORZA, «Cristianismo ilustrado y reforma política en Fray Miguel de Santander», Cuadernos Hispanoamericanos, 214 (octubre 1967), 73-107; el de M. REvUELTA GonZÁLEZ, «Actitudes opuestas de dos obispos santanderinos ante la guerra de la Independencia», en La Guerra de la Independencia (1808-1814) y su momento histórico, Santander, 1982, tomo II, pp. 665-686; o el más reciente de N. RocHAIX, «L'Eglise d'Espagne et la France: le cas de Miguel de Santander», en J. SAugnieux, Foi et lumières dans l'Espagne del XVIII siècle, Lyon, 1985, pp. 37-72.

71 Archives du Ministere des Affaires Etrangeres, París (en adelante AAE), Correspondance Politique, vol. 679, f. 350. Carta del embajador La Forest al ministro de A. E. de Francia, Madrid, 18 de agosto de 1809.

72 F. J. Montalbán, Historia de la Iglesia Católica. Edad Moderna..., cit., pp. 400 ss; J. GodeСНОт, Europa y América en la época napoleónica ..., cit., pp. 120-121; 158-159.
} 
En España, mientras tanto, José I ordenaba la salida de todos los miembros de la Nunciatura y Tribunal de la Rota, encabezados por el nuncio Gravina, quienes según los informes del gobierno y, en particular, del realizado por Urquijo, mantenían secretamente relaciones con el clero regular y secular de la capital y de las provincias. Una decisión drástica del gobierno josefino, que La Forest, ariete en todo momento de la política de su amo y señor, no dudaba en aplaudir:

(...) No es una medida baladí haber cortado de raíz un árbol que tenía ramificaciones tan extendidas, y en un momento sobre todo en el que el gobierno está obligado a seguir adelante en muchas cosas, sin poder ponerse de acuerdo con la corte de Roma $(\ldots)^{73}$.

No queremos concluir este trabajo sin señalar que, por avatares de la historia, algunas de las más importantes propuestas del plan elaborado por Pradt habrían de recogerse casi medio siglo más tarde en el Concordato español de 1851. Una transacción histórica entre la Santa Sede y el gobierno español, fruto de largas y difíciles negociaciones iniciadas en 1844, por la que se ponía fin a casi tres décadas de continuas tensiones entre ambos poderes. Entre las cuestiones más controvertidas se hallaban precisamente, sin que podamos adentrarnos ahora en su estudio, las que siguen: renovación del patronato regio otorgando a la Corona amplios derechos en asuntos eclesiásticos, en la línea del regalismo más genuino; reconocimiento de la desamortización eclesiástica como un hecho jurídicamente válido e incontrovertible (art. 42); nueva configuración del mapa diocesano, coincidiendo en algunos casos con el proyecto de 1808 (art. $5^{\circ}$ al $\left.7^{\circ}\right)$; y, sobre todo, financiación del culto y del clero por el Estado (art. 31 al 36) ${ }^{74}$.

\section{APÉNDICES}

Reproducimos a continuación dos documentos correspondientes al legajo relativo al plan de reforma eclesiástica elaborado por Pradt, ante la imposibilidad de publicarlo íntegramente por su extensión (56 folios), y por el deterioro de algunas partes del texto.

${ }^{73}$ AAE. Ibidem, f. 164 y vto. Carta del embajador La Forest al ministro de A. E. de Francia, Madrid, 8 de junio de 1809 .

${ }^{74} \mathrm{El}$ Concordato de 1851 ha sido objeto de numerosas y polémicas interpretaciones. La monografía moderna de mayor interés es, sin duda, la de J. PÉREZ DE AlHAMA, La Iglesia y el Estado español. Estudio histórico-jurídico a través del Concordato de 1851, Madrid, 1967. Un breve pero sustancioso análisis de este Concordato puede verse en V. CARCEL, «El liberalismo en el poder (1837-1868)», en R. García Villoslada, Historia de la Iglesia en España, Madrid, 1979, tomo V, pp. 154-158. El texto íntegro del Concordato se halla en el Apéndice de dicho tomo, pp. 719-730.

Hispania Sacra, LX

121, enero-junio 2008, 267-295, ISSN: 0018-215-X 


\section{$\mathrm{N}^{\circ}$ 1: CARTA DEL CONDE ROEDERER A JOSE I BONAPARTE. PARÍS, 20 DE MARZO DE 1809}

Sire:

J'ai l'honneur d'adresser à Votre Majesté un travail que l'archevêque de Malines (De Pradt) a fait pour l'Empereur concernant le clergé d'Espagne et l'emploi de ses biens. Il applique les dixmes au trésor de V. Majesté, et fait précisément les mêmes operations qui ont eu lieu su le clergé de France du temps de l'assemblée constituante. Ce travail a été fait en Espagne même pendant le séjour de l'archevêque avec S. M. Imp. Il me l'a remis, je le suppose, pour vous être présenté; je désire fort que le fonds du système soit praticable. Il est certain que la dixme du produit brut au profit du clergé et incompatible aven une contribution foncière de quelqu'importance, et incompatible avec les intérêts de l'agriculture; car le plus inégal et le plus décourageant des tributs est celui qui se proportionne au produit brut et ne tient aucun compte du plus ou moins d'avances el de travail que l'agriculteur est obligé de mettre à la terre pour obtenir ses produits.

J'attends, Sire, que Votre Majesté ai dit positivement si elle quitte Madrid et va dans l'Andalousie, ou si elle reste dans la capitale pour aller lui offrir mes respectueux hommages, ou différer mon départ jusqu' au temps de son retour à Madrid.

Je suis avec le plus profond respect, Sire, de Votre Majesté, le très humble, très obéissant et très fidèle serviteur. Roederer.

Paris, le 20 de mars 1809.

(ARCHIVES NATIONALES. Paris. 381 Archive Privée Joseph Bonaparte, pièce 17 , dossier 2 , cahier 1 ).

\section{$\mathrm{N}^{\circ}$ 2: CAPÍTULO DUODECIMO: BASES DEL NUEVO ORDEN ECLESIASTICO EN ESPAÑA}

L'ancien ordre ecclésiastique est aboli...

Un nouvel ordre y sera substitué à commences du premier Janvier 1810.

Toutes les dixmes de quelque nature qu'elles puissent être seront abolis le premier Janvier 1810.

Tous les Bienfonds du Clergé, Bâtiments, Mobiliers, Contrats sur l'Etat et sur les particuliers, sont déclarés Domaines Nationaux.

Tout ce qui ne sera pas reconnu nécessaire pour le culte sera vendu.

Les forêts au dessus de 400 arpens sont réservées et exceptées de cette vente. 
Celles au dessous de 400 arpens sont également réservées quand elles ne seront pas séparées d'autres parties de Bois Nationaux par une distance de plues de 300 Toëses.

Le produit de ventes sera employé pour les besoins du Gouvernement. Pour la garantie de la dette nationale actuelle, et de celle qui pourrait encore avoir lieu. Pour l'établissement d'une Caisse d'Amortissement.

Le $10^{\text {ème }}, 12^{\text {ème }}$ ou $15^{\text {ème }}$ des ventes sera réservé pour être employé aux Travaux publics, tels que les ponts, les chemins, les Canaux de navigation, et d'arrosement, les Ports, et autres objets d'utilité publique.

Le Clergé recevra un traitement annuel fixé par l'Etat et payé par le trésor public.

Le Clergé supprimé recevra des pensions.

Toute juridiction exempte de l'Ordinaire est supprimée.

Il sera fait une nouvelle Circonscription des Paroisses, de manière à ce que le nombre n'excéda pas celui de 16000 .

La réduction aura lieu principalement sur les Paroisses des villes, qu'on réduira autant que possible.

Le nombre des fêtes sera réduit.

A l'avenir le Clergé d'Espagne sera compté ainsi qu'il suit:

-Les Archevêques

-Les Evêques

- Les chapitres de cathédrale

-Les vicaires généraux

- Les curés

-Les vicaires

-Les Séminaires

-Les prêtres invalides pensionnés

-Une Ecole de prédication

-Quelques bénéfices à la nomination du Roi

Les Diocèses seront divisés par Métropoles.

Les chanoines des cathédrales seront nommés par les Evêques.

Les curés de même.

Aucun Ecclésiastique ne pourra exercer sans l'approbation de l' Evêque. 
Les Séminaires seront sous la surveillance des Evêques, et les supérieurs nommés par eux.

Ils désigneront les Ecclésiastiques susceptibles de pension de retrait.

Ils désigneront aussi les Ecclésiastiques dans le cas d'être admis dans l'Ecole de prédication.

Les vicaires seront payés par les Communes qu'ils desserviront, et ils partageront par moitié avec les curés les droits d'étole ou le casuel.

Un Concordat sera réglé avec le Pape.

(ARCHIVES NATIONALES. Paris. 381 Archive Privée Joseph Bonaparte, pièce 17, dossier 2, cahier 1. Table de matières (s.d). Chapitre douzième: Bases du nouvel ordre Ecclésiastique en Espagne). 